\title{
EXPLOITATION OF COMMUNICATION BASED TECHNOLOGY IN TERMS OF ASSISTING THE STUDENTS OF THE HELLENIC OPEN UNIVERSITY TOWARDS THE DEVELOPMENT OF THEIR WRITTEN ASSIGNMENTS
}

\author{
Koukousouri Vasiliki, Karaoulanis Andreas MBA MSc Eng MSc B Eng \\ Hellenic Open University, Thermi Thessaloniki \\ Vaskoukou03@gmail.com \\ Cardiff University, Thessaloniki Thermi \\ andrekaraoul@gmail.com
}

\begin{abstract}
The purpose of this research is to investigate the views of the postgraduate students of the Hellenic Open University during the 2016-17 academic year on the possibilities of using internet based platforms and computer technology in general for the preparation of their written work in such a distance learning degree. Our sample was students 24 women and 6 men. All students in the same degree in the above mentioned academic year. Students were asked to complete a written questionnaire that was posted on the internet, while they were ensured for their anonymity. Data analysis was done by following a quantitative approach via the usage of the SPSS24 statistical software. The most important findings of the research were that of all forms of internet and computer based technology that was used in order to assist students during their studies, the forum, the emails and the usage of phone conversations with students and lectures were the ones that were mostly related with their written assignments. In terms of their educational needs in general, they were covered by email, forums, telephone communication and they also chose to videoconferencing. Generally speaking, they have shown that internet and computer technology are essential in distance learning education. Finally, students wanted to improve their communication with their lectures, would like to increase their telephone communication with them and to give answers to their questions via the forum usage.
\end{abstract}

Keywords:Internet, communication, e-mail, forum, distance education, Hellenic Open University, telephone.

Academic Discipline:Education, Management

TYPE (METHOD/ APPROACH):Research in Educational Methods

Language : English

Date of Submission : 2018-02-26

Date of Acceptance : 2018-03-20

Date of Publication : 2018-04-30

ISSN : 2278-7690

Volume : 09 Issue : 1

Journal : INTENATIONAL JOURNAL RESEARCH IN EDUCATION METHODOLOGY

Publisher : CIRWORLD

Website : https://cirworld.com

This work is licensed under a Creative Commons Attribution 4.0 International License. 


\section{INTRODUCTION}

Distance education is basically a learning method, an educational concept which is linked to special teaching material and has a differentiated role for the teacher as opposed to the traditional teacher model (Panagiotakopoulos, Lionarakis, Xenos, 2003).

Panagiotakopoulos et al. (2003), defined distance education as an interactive communication between two stakeholders (the teacher and the learner) who are in different geographical locations and communicate through technology. They also state that all researchers consider the contribution of technology indisputable. Additionally, internet and computer technology is an important tool for writing written assignments in the distance education.In recent decades, the rapid growth of computers and the Internet has led to the emergence of a new form of education, the distance learning, which fills the gap that existed as the traditional form of education, the on campus one, wasn't able to bridge the distance between the lecturer and the student in cases when they both were in different geographic locations. (Panagiotakopoulos et al., 2003).

Zygouris and Mavroidis (2013), also agreed on the importance of communication between the teacher and trainees in the distance education. They point out that the most desirable form of communication,in terms of answering questions about written assignments, is the interpersonal one in addition to the electronic and the communication via the telephone. The online communication platform offers the possibility of helping the students to communicate with a professor- consultant, the announcement of the topics of the written assignments and the specific instructions needed, as well as the posting of the educational material. They conclude that communication can be improved by the contribution of technology, as the lecturer can use in that way specific communication tools in order to make learning active and constructive (Zygouris\&Mavoyidis, etc.).

Markellos(n.d.), refers to the daily usage of technological tools by the students, both for sending and receiving e-mails, as well as for searching for information, communication with the lecturer and with fellow students and for participating in forums and sites or various chat-rooms.

Inzidou (2014), reports that the trainee is physically distant from the trainer and uses the technology to communicate with him in terms of any questions that will arise about the learning process. According to Lionarakis (2001), the development and use of technology (software, computer, internet, e-mail platforms, etc.) is directly linked to the promotion of the educational process in the distance education industry.

Tzotzou and Turambelis (2015), highlight the potential for computer based interaction, which covers the needs of trainees and ensures their independence.Nirgal (2002), emphasizes that educational research on distance education observes that learning is focused on the trainee whileit motivates him to act in a high-tech environment (Harmon \&Hirum, 1996; Wagner \&McCobs, 1995, cited inNirgal, 2002). Solomon (1996, cited in Nirgal, 2002), defines the role of the lecturer in charge in a virtual learning environment as diagnostic and regulatory. She should collaborate with student groups and help them make progress on their own by working on the PC, mainly towards the submission of their written assignments.

The elimination of the physical distance separating the students from the lecturer is also highlighted by lliadou and Anastasiadis (2010). The role of the lecturer is multidimensional through her communication with the learner, something which is difficult as they are not in the same place. This obstacle can be overcomebythe right usage of technology and the immediate and rapid response of the lecturer to their students who are struggling to submit their written assignments (Eliadou\&Anastasiadis, 2010).

Iliadou (2011), underlines the importance of the usage of telecommunications in distance education, as through them the instructor provides advice and information without reducing the autonomy and the responsibility of the student.

Vassala and Andreadou (2009), emphasize that the "real" communication (direct and indirect) have as their primary element the two-way interaction between students and lecturers. Direct communication takes place during the group counseling meetings, i.e. interpersonal. Indirect communication is done by writing i.e. a conventional mail or an e-mail.

Many researchers argue that technology is simply a secondary tool while the primary one is the communication and interaction of students with their lecturer and other students (Abrahamson, 1998; Caspi\&Gorsky, 2006; Ching, Murphy, \&Jekings, 2002; Holmberg , 1995 ;Keegan,2001;Kelsey \& D'Souza, 2004;Tait, 2004).

In the Tzotzou and Bijlaki (2013) survey, the respondents - students propose the revision and modernization of the educational material in terms of its content and polymorphism. They also call for the enrichment of 
existing material with software, multimedia, audio-visual and other applications. The educational material that the Hellenic Open University is using is falling short in many aspects, like in polymorphism and adequacy (Tzotzou\&Bijlaki, 2013).

\section{OBJECTIVE AND RESEARCH QUESTIONS}

\subsection{Formulation Of The Research Objective}

The aim of this research is to investigate the views of postgraduate students in the Hellenic Open University and specifically those who follow the ERP51 (Educational Research in Practice) module on how to exploit the potential of technology in education in order to help them with their written assignments.

\subsection{Formulation OfThe Research Questions}

The research questions are the following:

1. How does the use of technology(independent variable), relates to the submission of written assignments (dependent variable), in the Hellenic Open University's (HOP) postgraduate programs? (correlation question).

2. How often are the technological means (independent variables), used by graduate HOU students in order to help them meet their educational needs and objectives (dependent variables), mainly for the development of their written assignments? (descriptive query).

3. How do students believe that they can improve the effectiveness of their communication via the usage of technology (dependent variable), in order to prepare their written assignments? (descriptive query).

4. How important is for students to use technology (independent variable,) during their postgraduate studies in the $\mathrm{HOU}$ regarding the preparation of their written assignments (dependent variable)? (descriptive query).

\section{OPERATIONAL DEFINITIONS}

\subsection{The TermTechnology}

In education, technological tools, are used by both lecturers and students, in order to promote the learning process and to achieve the best possible learning outcomes (Cole, 2004, op. Cit., In Yomelos, 2010).

Information and Communication Technologies are defined as "design, development, implementation, support or management of information systems based on computing technology, namely software applications and

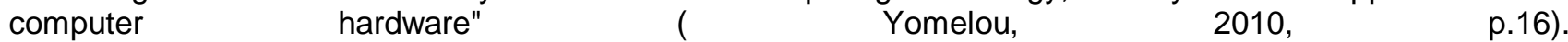
In this research, we examined what form of communication technologiesthat the students use for the preparation of their written assignments (teleconferencing, telephone communication, e-mail, skype, forum, chatroom or something else).

\subsection{The Term Educational Needs}

In distance learning, students follow a more personalized and free- way of studying by organizing their free time in order to be able to respond to their studies and to achieve their goals by using the educational material with in a proper way and with outmost responsibility (Kokkos, 1998, op. Tzotzou\&Bijlaki, 2013). In our research, we measured whether the use of communication based technology covers the educational needs of postgraduate students in the HOU and how often it is used in order to meet these needs.

\subsection{The Term Communication With The Lecturer}

Distance learning creates fear and insecurity for some students due toinadequate communication with the lecturer, or due to the lack of familiarity with technology (Tzotzu\&Bialaki, 2013). Communication with the lecturer greatly relieves stress and helps solve their problems. Communication can be interpersonal private,face to face, or via telephone, or e-mail, or it can also be via some kind of teleconferencing (i.e. skype, blue jeans etc.). Students communicate with the lecturer primarily for feedback on their written assignments. In this research, we have investigated how this communication can be improved. 


\subsection{The Term Written Assignments In Distance Learning Education}

Written assignments in distance learning, especially in $\mathrm{HOU}$, offer practice and a learning opportunity to the learner (Spanaka, 2010). Nikolakakis (2013) stresses that the preparation of the written assignments is compulsory for the completion of the modules within the curriculum defined by the HOU. He continues that the subject of the work is related to the subject of the studies and their preparation is required so that the student can take part in the final examinations.

\section{OBJECTIVE DOCUMENTATION AND RESEARCH QUESTIONS}

With the rapid invasion of PCs and the Internet in people's everyday lives, new technologies have tried to serve education, leading many universities around the world to use them for distance learning purposes (Panagiotakopoulos, Lionarakis\&Xenos, 2003). Today students, can have access via their computers to educational material and libraries and of course, to the usage of technology for the completion of their written assignments. Internet communication for the learning process may be synchronous or asynchronous or both (Panagiotakopoulos et al., 2003).

$\neg$ Synchronous communication: Telephone communication, audio session (PC teleconferencing), visual session, white board session, application of chat- rooms. It seeks to give answers to questions regarding the preparation of the students' written assignments and guiding the teacher in terms of the educational material.

$\neg$-Asynchronous communication: Usage of faxes, PC software, video tapes, audio tapes, compressed video, e-mail, etc.

Panagiotakopouloset al. (2003), emphasizes that there are special software platforms in which some activities can take place with regard to the preparation of written assignments, such as student statements, e-mails, modern communication between the lecturer and the students and between students. Specifically, e-mails is the almost exclusive means of communication between students, as the work is delivered only electronically. The students' communication with thelecturer proves to be valuable in terms of coordinating and guiding the learning process in order to proceed with the adaptation of the guidelines. (Panagiotakopoulos et al., 2003). New information and communication technologies offer many new possibilities and ways thru which they can create innovative and effective environments towards the promotionof the learning process and the transformation of the relationship between the lecturer and learner without this implying that can substitute the role of the lecturer and the interpersonal communication at distance learning (Zygouris\&Mavroidis, 2013). New technologies in distance learning programs enable students to immediately and quickly communicate with the lecturer in charge in order to encourage, guide and solve questions about written work (Zygouris \& Mavroidis,etc.).

Also, Eliadou (2011) reports that students communicate with the lecturer in order to be assisted, among other things, to their assignments too. Therefore, the lecturer carries out a multi-faceted and demanding work, which results in the need of constantly updating their knowledge and education in order to develop their social and communication skills (Clay, 1999, cited in lliadou 2011).

\section{METHODOLOGICAL FRAMEWORK FOR RESEARCH}

\subsection{Method}

The approach followed in this research is the quantitative one, which was implemented by the distribution of a written questionnaire to postgraduate students that attend the ECD51 module during the academic year 20162017. The research problem, research questions and bibliography lead the researcher to choose quantitative instead of qualitative research (Creswell, 2016). The researcher formulates the research problem based on trends and due to the need to explain why something happens, to measure and to explain some variables (Creswell,

2016).

The advantages of quantitative analysis can be divided according to Denscombe (2010) into:

a)Scientifically: Quantitative data lead to a variety of statistical techniques based on the principles of mathematics and probability, thus giving the analysis a scientific perspective.

b)Criteria of trust: statistical tests give researchers confidence in terms of interpretation of the data and the confidence they have in the findings. 
c)Measurement criteria: the analysis of quantitative data provides a solid foundation for description and analysis. The interpretations and findings are based on quantitative measurements rather than impressions, as well as can be checked for their authenticity.

d)Analysis: data can be analyzed relatively quickly given that it has been prepared and properly planned.

e) Presentation: Tables and diagrams provide an efficient way of organizing quantitative data. Wide use of PCs and the Internet, as well as special software, helps both the design and the statistical analysis (Denscombe, 2010).

Because we have tried to describe attitudes, opinions, behaviors or even population characteristics using a written questionnaire, we have followed a peer-reviewed or sample research project (Creswell, 2016), compiling quantitative numerical data that was statistically analyzed to describe answers' trends and to check our research questions (Creswell, 2016).

This research has focused on the measurement of some variables (technology utilization, educational needs coverage, improvement of communication with the lecturer) in relation to the preparation of the written assignments in the postgraduate program of $\mathrm{HOU}$ (ECD51). The trends and correlations of the variables were analyzed. Often, in polled research designs, researchers associate variables using statistical analysis and interpretation of results (Creswell, 2016).

\subsection{Target And Sample Population}

The term "representative" refers to the selection of individuals of a population sample provided that can characterize the studied population as a whole. A population is a group of people sharing same features, whiletarget population is a set of people with common characteristics. In our research we used a convenient sample by selecting participants who were willing and available to participate (Creswell, 2016).

One problem that occurred as a result of the usage of such convenient sample, is that we cannot say that the participants were representative of the whole population. Our sample was 30 students attending the ECD 51 module in a specific postgraduate program of the HOUduring the academic year 2016-2017, while $80 \%$ were women, and $20 \%$ were men, as shown in the following circular diagram (Figure 4.1).

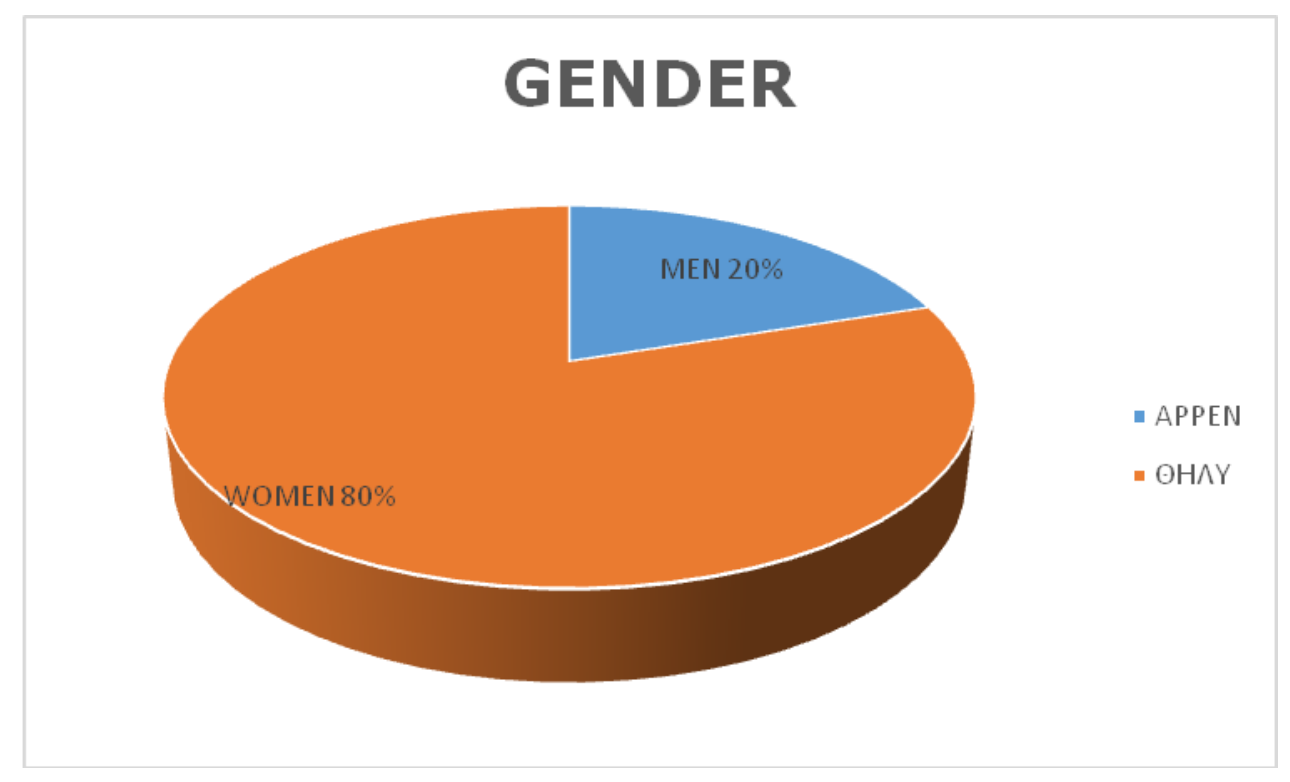

Figure 4.1. Circular sex chart.50\% were aged between 25-35, 27\% 36-45, 20\% 46-55, and $3 \% 56$ and above (Fig. 4.2). 


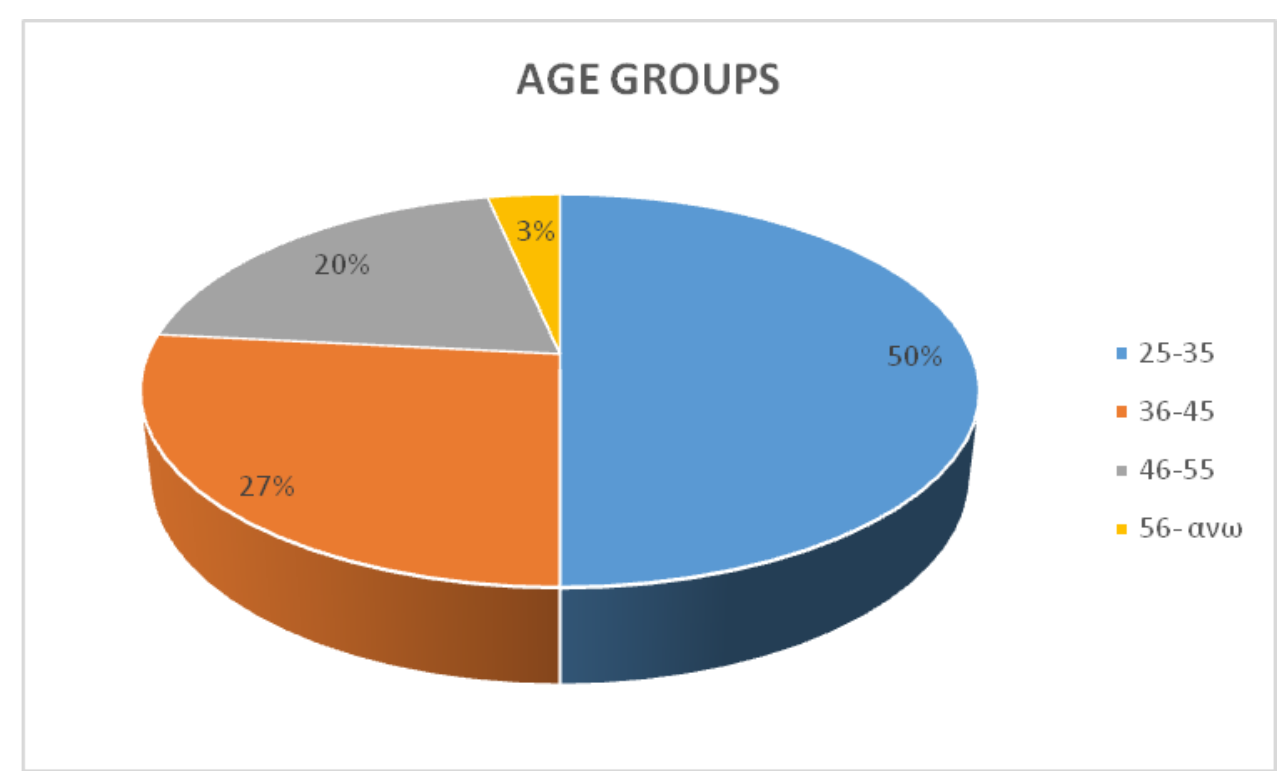

Figure 4.2. Circular diagram of age groups.

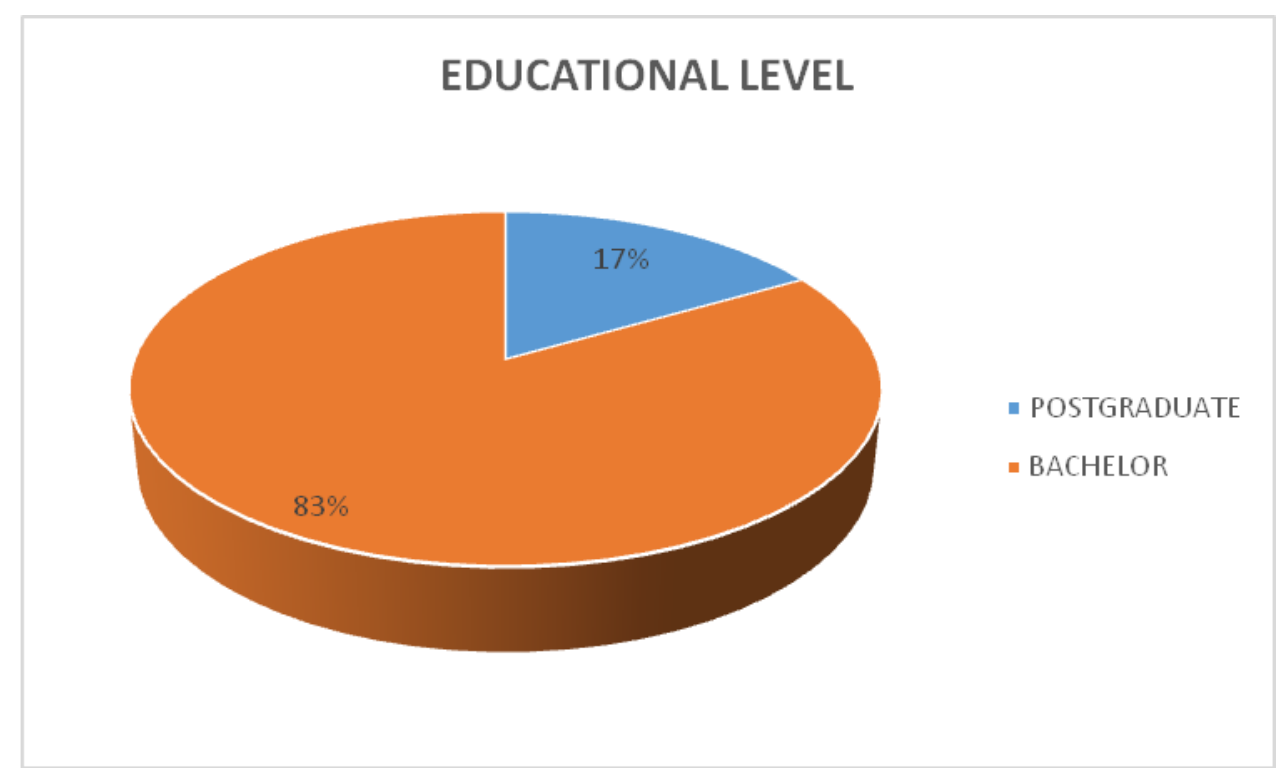

Figure 4.3. Educational level. $83 \%$ hold a Bachelor degree and $17 \%$ hold a postgraduate degree.

\subsection{Questionnaire}

According to Robson (2010), the questionnaire is the easiest way to gather information about events involving a large group of people, while they help produce a large set of data at a relatively low cost and in a relatively short period of time. The anonymity of the respondents is and should always be guaranteed.Denscombe (2010) stresses that questionnaires can be used in a wide range of research situations, such as when a large number of respondents are used in many locations when frank information is required relatively briefly and undoubtedly, and when there is a need for consistent data from similar questions without face to face 
interaction.In general, questionnaires are very easy to be organized, while they can provide predefined responses and there is only little risk of data being influenced by interpersonal factors.

Predefined answers can help the respondents as they do not have to think about how they will be expressed (Denscombe, 2010). Also the data collected by the researchers will be entered into a data folder where it will be analyzed in order to eliminate the human error (Denscombe, 2010). On the other hand, there are some drawbacks that we have to take into account. Questionnaire surveys typically have a low response rate and we do not know whether the sample that responded is representative. Also, some questions may be misinterpreted and misunderstood, or the respondents may have not seriously took the survey (Robson, 2010).

Another drawback of the predefined questionnaires in a quantitative survey, is that it is possible to reflect the researcher's point of viewinto the respondents' answersas it is guided via the formations of the questions as designed by the researcher (Denscombe, 2010).

In this survey, which has a quantitative direction, a written questionnaire was posted on the Google Forms platform on the internet, which was addressed to postgraduate students of the HOU who attended the ECD 51 module. The questionnaire (see ANNEX I) includes nine closed-ended questions. The first three refer to the demographics of the participants, four use the Likert scale ranging from 1 to $5(1=$ absolutely disagree, $5=$ totally agree) and finally the last two are of closed type with predefined answers. On the Google Forms platform, 66 people,who were attending the ECD 51 module, completed the questionnaire, out of which only 30 responses were utilizable.

\subsection{Research Process}

The first stage of a research is the clear identification of the research problem that leads us to the need for research (Creswell, 2016). The authors of this paper initially set the research objective and then made the necessary literature review.

In order to carry out this research, the quantitative method, which was implemented by posting the questionnaire on the google forms questionnaire platform, addressed to postgraduate students of the HOU, who attended the ECD 51 module. It is very important here to underline that the researchers were always very cautious regarding the respondents' anonymity. After the questionnaires were collected, initially 66 but only 30 usable, the quantitative data was processed by the SPSS 24 software. Finally, the quantitative data was aggregated and the results discussed / presented in order to draw conclusions.

Here it should be noted that population and sample determination was made by convenient sampling in which the researchers chose their participants because they were willing and available to participate so we cannot say that the participants were a representative sample of the population as a whole (Creswell, 2016).

\subsection{Reliability And Validity}

Reliability means that the values of a tool are stable and consistent. Values should be almost the same when the researchers use the tool several times at different points in time. (Creswell, 2016, pp. 159-160).

Validity is the extent to which all evidence point out to the intended interpretation of the test scores for the intended purpose. (Creswell, 2016, p.160).

In this survey, we used a written questionnaire because, as a tool, it has been extensively used in many quantitative and qualitative surveys in the past with reliable and valid results. The assurance of reliability depends on many factors and for this reason the questions must be clear, the procedures must be the same and standardized and of course, the participants should not be tired or nervous or misinterpret the questions (Creswell, 2016). To control the inner consistency, we used the alpha factor (Cronbachalpha) (Creswell, 2016) because it provides a factor very important to assess the consistency of a tool's values (see Table 1). The alpha factor must be $>0.7$. In our case it was 0.716 , so we can say that our tool was quite reliable.

In terms of validity, it would be useful to look at how other researchers interpreted this tool and how they evaluated it by looking at the data provided by them (Creswell, 2016). The first thing to check is whether our 
questions are related to our research questions and the purpose of the survey. In our questionnaire there is a validity of content as the questions "count" on what it was written about.

\section{Table 1.Reliability S}

\section{Reliability Statistics}

\begin{tabular}{r|r|r}
$\begin{array}{c}\text { Cronbach's } \\
\text { Alpha }\end{array}$ & $\begin{array}{c}\text { Cronbach's } \\
\text { Alpha Based } \\
\text { on } \\
\text { ondandardized } \\
\text { Items }\end{array}$ & N of Items \\
\hline .716 & .499 & 17 \\
\hline
\end{tabular}

\section{METHOD OF DATA ANALYSIS}

In descriptive queries, we use a descriptive statistical analysis that helps us sum up overall trends or directions in our data (Creswell, 2016). In this way, we will find mean, median, predominant (mode), standard deviation, minimum, and maximum values. We compared our findings and came up with some conclusions.

When we associate variables we use inductive statistics. We see the values of our sample and use them in order to draw conclusions about the population (Creswell, 2016). In our survey we used the t-Test (for independent samples) as our correlation question consists of an independent categorical variable with two categories and our dependent variable was continuous.

\section{RESULTS}

The analysis of the data was done with the SPSS24 statistical program and we came up with the following major findings:

In our correlation question "How the use of communication based technology is related to the development of the students' written assignments in our post-graduate programs? "according to our research it was proved that the use of e-mail had a level of significance $p=0.815$ (whereas $p$ should be $p<0.05$ ) and therefore there is no statistically significant difference. The same is true for the telephone communication with $p=0.066$, so we do not notice a statistically significant difference, as in the teleconferencing $p=0.135$. While on the forum it was found that $p=0.001$ and therefore there is a significant statistical difference. In chat room $p=0.237$ there is no statistically significant difference here as well as in skype $p=0.174$. Whilst choosing to use an alternative communication based technology form, no one answered "yes". So only the use of the forum seems to be related to the development of the students' written assignments.

Following the responses to the question: "How often the communication based technologyis used by the postgraduate students in the distance postgraduate education in the $\mathrm{HOU}$, in order to meet their educational needs and objectives, mainly for the preparation of their written assignments?", our research has shown average 3.93, median 4.00, prevalent value $(\operatorname{mode}) 4(\min =1$, max. $=5)$, standard deviation $=1.202$, frequent use of communication based technology.

Now that their educational needs are met by using communication based technology, the following have been proven:

- For the use of e-mail: mean $=3.83$, median $=4.00$, mode $=4(\min =2$, max. deviation $=0.791$.

- For the telephone communication: mean $=3.53$, median $=4.00$, mode $=4(\min =1, \max =5)$, std deviation $=1.306$.

- For teleconferencing mean $=3.03$, median $=3.00$, mode $=4(\min =1, \max =5)$, std deviation $=$ 1.402.

- For forum average $=3.37$, median $=4.00$, mode $=4(\min =1, \max =5)$, std deviation $=1.426$.

- For chat room mean $=2.30$, median $=2.00$, mode $=1(\min =1, \max =5)$ std deviation $=1.264$. (Mean $=2.00$, mode $=1$ ), std deviation $=1.450$, while

- Choosing to use another form of communication based technology was: mean $=1.90$, median $=1.00$, mode $=1(\min =1, \max =4)$, standard deviation = $1.125($ see Appendix II, bar graphs 2,3,4,5,6 \& 7, pp. 28-31).

The above mentioned results mean that students feel that their educational needs are covered most by telephone and e-mail, and then by teleconferencing and forum. 
To the question: "How do students believe that they can improve the effectiveness of their communication via the communication based technologyin order to help them with the preparation of their written assignments?" our research first showed that:

- Students agree that communication with the teacher should be improved with mean $=4.57$, median $=$ 5.00. mode $=5(\min =3, \max =5)$.

- The ways in which they suggest this improvement are: Reinforcement teachings (frequency $=4$, perc. $=13.3 \%$ ), recorded lectures (freq. $=5$, perc. $=16.7 \%$ ), teacher's answers to questions through the forum (freq. $=10$, perc. $=33.3 \%$ ), increase in telephone communication (freq. $=10$, perc. $=33.3 \%$ ), , circular diagram 4, p.31).

In other words, students want to increase the number of telephone conversations with the lecturer and to answer their questions through the forum.

In our last question: "How important do students think that is the contribution of communication based technology to the preparation of their written assignments", the survey showed average $=4.30$, median $=$ 4.50 , mode $=5(\min =1, \max .=5)$, std deviation $=1.022$. This means that they consider as very important the contribution of communication based technology to the preparation of their written assignments.

In terms of what forms of communication based technology, students consider as essential for the development of their written assignments, $83.3 \%$ responded by e-mail, $83.3 \%$ via the forum, $70 \%$ via the telephone communication, $53.3 \%$ via the teleconference, $16.7 \%$ via the chat room, and $36.7 \%$ via skype (see Annex II).

\section{DISCUSSION OF THE RESULTS}

When the parties(the lecturer and the students) are located in different geographical areas, they communicate through technology and make use of it for the preparation of their written assignments (Panagiotakopoulos et al., 2003). In our survey, it was precisely the fact that students perceived some forms of technology to be necessary for the development of their assignments: e-mail and forum $83.3 \%, 70 \%$ telephone conversation, followed by videoconferencing, chat room \&skype. For the students' preference to use e-mail, reports were made by Markelou (n.d.), Iliadou (2010), Vassala and Andreadou (2009).

Our research has shown that the forum is related to the students' written assignments development with $p=$ $0.001<0.05$, which is in line with the reports of Zygouris and Mavroides (2013). Inzidou (2014) reports the direct correlation of technology with the educational process in the HOU. Our research has shown a high average ( 4.30 of the Likert $1-5$ scale) in terms of whether students consider the use of technology for the development of their written assignments to be significant.

Zygouris and Mavroidis (2013) report that the communication of students with the lecturer can be improved. Our research first showed that students are of the opinion that communication with the lecturer should be improved $(\mathrm{MO}=4.57,1-5)$ with $33.3 \%$ greater the desire for teacher's answers through forum and increase of telephone communication. The elimination of the physical distance between the student and the lecturer through technology is also underlined by lliadou and Anastasiadis (2010).

There is a need to modernize and enrich the educational material in HOU in order to meet the educational needs (Tzotzou\&Bijlaki, 2013). In our research we found the need of students to meet their educational needs in other ways of communication beyond email and telephone communications, which had high rates, such as teleconferencing (prevailing value $=4)$ and forum $(4=4)$.

This research was limited to the views of the postgraduate students of theHOU who were attending the ECD program during the year 2016-2017. It is suggested that a future research should involve all postgraduate students of the HOU or even the undergraduates.

\section{RESTRICTIONS AND DIFFICULTIES OF RESEARCH}

A major problem that from the beginning the researchers encountered waswhether the necessary number of questionnaires would be completed, as not all students were familiar with each other and it was in their discretion and willingness to participate in the research. At the end, 66 students answered to the questionnaire. The questionnaires were examined in terms of bias creation, because the respondents might have misinterpreted the questions, resulting in ambiguity or, as reported by Robson (2010), the self-completed questionnaires may be subject to bias of the response. 
Another issue was that because our sample was finally 30 individuals ( 24 females and 6 males) and those selected by convenient sampling, we were unable to have a representative sample of the whole students' population and therefore we cannot make a generalization in terms of the results. Our sample was consisted only of students of the HOU who attended the EWC51 module, so it was not representative of the entire $\mathrm{HOU}$. Finally, due to time constraints, we were unable to gather and analyze a larger sample. We have also taken into account the ethical issues that arose such as respect for the participants, the protection of their autonomy, the assurance of their voluntary participation, their fairness and anonymity (Creswell, 2016).

\section{CONCLUSIONS}

Several conclusions can be drawn from this survey. The most important ones are that the postgraduate students of our sample prefer emails in terms of how to communicate with the lecturer and with each other in order to help them develop their written assignments.

Another very important result is that HOU need to modernize in order to catch up with the contemporary educational trends in distance learning.

Finally, the overall climate was that students in their distance education courses need specific help which should be provided by their lecturer via the usage of the proper educational and technological means which are mainly based on communication. Communication is the alpha and the omega in education, so especially in distance learning where the two parts (lecturer and student) don't have physical contact, communication can be the decisive factor in terms of the knowledge dissemination.

In terms of future research, a good proposal is to gather a more representative sample and/ or to take the research on a larger scale by having a sample from many programs in both undergraduate and postgraduate education of the $\mathrm{HOU}$.

\section{REFERENCES}

1 Creswell, J. (2016). Research in education. Athens: publishing group of Ion.

2 Zygouris, F., \&Mavroidis, H. (2013). Learning in groups and developing learning communities in distance learning. In A. Lionarakis (eds.), Proceedings of the 7th International Conference in Open \& Distance Learning "Learning Methodologies". November 2013. (pages 66-72) .7 (5B). Athens, Greece: Publications of the Greek Open and Distance Education Network. Retrieved on 11/12/2016 by: http://eproceedings.epublishing.ekt.gr/index.php/openedu/article/view/553/532

3 Vassala, P., \&Andreadou, D. (2009). Support from teachers, counselors and fellow students in distance learning. The views of the graduates of the postgraduate program "Education in Education" At the 5th International Conference in Open \& Distance Learning. November 2009 (pp. 56-69) .5 (2A). AthensGreece: Publications of the Greek Open and Distance Education Network. Retrieved on 12/10/2016 by: http://eproceedings.epublishing.ekt.gr/index.php/openedu/article/view/438

4 Yomelou, C. (2010). ICT and Education: Skills Assessment. November 2010 (pp. 8-15). University of Piraeus, Piraeus. Retrieved on 14/12/2016 from: http://dione.lib.unipi.gr/xmlui/bitstream/handle/unipi/4099/Giomelou.pdf?sequence=2\&isAllowed=y

Denscombe, M. (2010) The Good Research Guide .England: Open University Press.

5 Eliadou, Ch. (2011). Contacting Teacher - Consultant and Students in Distance Learning: SEP Views of the EEEF65 of the EAP. Open Education / Open Education International Journal. 7 (1) pp. 6-18. Retrieved on $\quad 15 / 10 / 2016$ by: http://journal.openet.gr/index.php/openjournal/article/view/9765/9896

6 Iliadou, Ch., \&Anastasiades, P. (2010). Contact of professor - counselor and students in distance learning: Students' views in the framework of the School of Economics. Open Education / Open Education International Journal. 6 (1) $\sigma \sigma .30-44$. Retrieved on 16/10/2016 from: http://journal.openet.gr/index.php/openjournal/article/view/9751/9884

7 Inzidou, Ch. (2014). Open and Distance Learning. TEl of Kavala, Kavala. Retrieved on 11/12/2016 by: http://digilib.teiemt.gr/jspui/bitstream/123456789/457/1/022014025.pdf

8 Markellou, P. (xn). Possibilities of exploiting the social software in AXAE. At the 7th Pan-Hellenic 9Conference with International Participation. Xh (pp 1-8). Retrieved on 11/12/2016 by: 
http://korinthos.uop.gr/ hcicte10/proceedings/172.pdf

10 Nikolakaki, E., Koutsouba, M., \&Lykeas, G. (2013). Written Works and Group Counseling Meetings as important pedagogical tools in supporting self-regulated learning strategies in the EAP environment. At the 7th International Conference in Open Education and Distance Learning November 2013 (pp.167-173). 7 (1A). Athens- Greece: Publications of the Greek Open and Distance Education Network. Retrieved on $12 / 12 / 2016$ http://eproceedings.epublishing.ekt.gr/index.php/openedu/article/view/538/516

11 Nir-Gal, O. (2002). Distance Learning: The role of the Teacher in a Virtual Learning Environment. Retrieved on 16/10/2016 from: http://www.achva.ac.il/sites/default/files/achvafiles/maof-book/8/2002-2pdf

12 Panagiotakopoulos, Ch., Lionarakis, A., \&Xenos, M. (2003). Open and Distance Learning: Tools of Information and Communication Technologies for Effective Learning. In the Proceedings of the 6th Hellenic European Research on Computer Mathematics and its Application Conference. HERMA 2003 (pp. 1-7). Athens - Greece: Publications of the Greek Open and Distance Education Network. Retrieved on $10 / 12 / 2016$ by:

http://citeseerx.ist.psu.edu/viewdoc/download?doi=10.1.1.414.2825\&rep=rep1\&type=pdf

13 Robson, C. (2010) Real-world research. Athens: Gutenberg publications

14 Tzotzou, M., \&Bialaki, N. (2013). Investigating Student Attitudes of the MSS "Learning in Education" for Distance Learning Personalized Learning of the EAP - A Case Study. International Journal of Open Education / Open Education, 9 (1), 76-93. Retrieved on 19/10/2016 by:

http://ejournals.epublishing.ekt.gr/index.php/openjournal/article/view/9803/9930

1. Tzotzou, M., \&Turambelis, M. (2015).

\section{ANNEX 1}

\section{HELLENIC OPEN UNIVERSITY(HOU)}

Editor of the questionnaire: KOUKOUSOURI VASILIKI POSTGRADUATE STUDENT OF THE HOU TO THE ECD THEMATIC UNIT51.

Introductory text: Dear colleagues, this questionnaire was designed in order to explore the views of students in the ECD Thematic Area 51 on the possibilities of using communication based technology for the preparation of written assignments in distance learning. I would ask you to participate in this survey and fill in the questionnaire. Your participation will of course remain anonymous. Thank you in advance!

\section{QUESTIONS}

1. Gender:

MALE

2. AGE: $25-35$

FEMALE

$36-45$

46-55

56 -plus

3. STUDIES: TEI - UNIVERSITY

POSTGRADUATE

DOCTORAL

4. Which of the following forms of communication based technology do you think are necessary for the preparation of written papers in HOUpostgraduate programs? (More than one answer can be selected).

E-mail

Contact via phone

Teleconferencing

Forum 
Chat room

Skype

Other

5. Using the following scale ( 1 to 5 ), please make a note of the most appropriate answer in the circle, the degree to which you believe your educational needs are met (search for educational material, communication with a teacher, solving questions, etc.) with the use of each of the following forms of communication based technology?

$\begin{array}{lll}12345 & \text { E-mail } \\ 12345 & \text { Contact via phone } \\ 12345 & \text { Teleconferencing } \\ 12345 & \text { Forum } \\ 12345 & \text { Chat room } \\ 12345 & \text { Skype } \\ 12345 & \text { Other }\end{array}$

1: Not at all, 2: Little, 3: Enough, 4: Very, 5: Too much.

6. How important do you consider the use of communication based technology in the preparation of written assignments in postgraduate programs of the HOU?

NO IMPORTANT

IMPORTANT

SIGNIFICANT

VERY IMPORTANT

EXTREMELY IMPORTANT

7. How often do you use communication based technology in postgraduate programs of the HOUtowards thepreparationof your written assignments?

NOT AT ALL

A LITTLE

FREQUENTLY

VERY FREQUENTLY

EXTREMELY FREQUENTLY

8. Do you agree that the effectiveness of the communication of postgraduate students in the HOU with the professor consultant should be improved?

COMPLETELY DISAGREE

DISAGREE

AGREE AND DISAGREE

AGREE

COMPLETELY AGREE

9. How do you think that the effectiveness of the communication of postgraduate students of the HOUwith the teacher - Advisor can be improved? (More than one answer can be selected).

REINFORCING TEACHING VIA TELECONFERENCING.

RECORDED LECTURES.

TEACHER ANSWERS TO QUESTIONS VIA THE FORUM.

INCREASE OF TELEPHONE COMMUNICATION. 
OTHER

Thank you very much for your participation!

\section{ANNEX 2}

\section{SPSS24 DATA ANALYSIS}

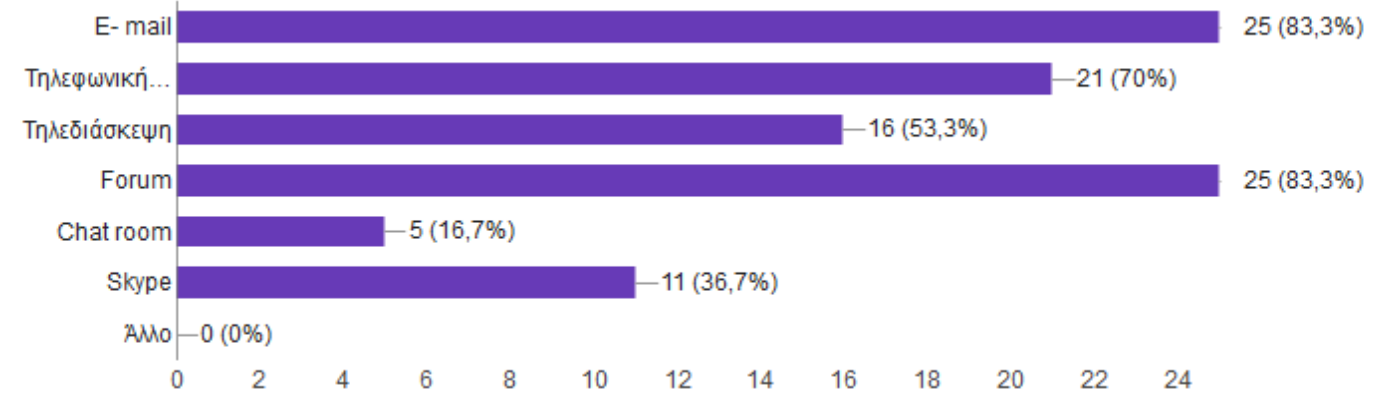

Bars chart 1.COMMUNICATION BASED TECHNOLOGY USAGE RATES

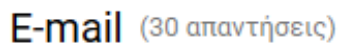

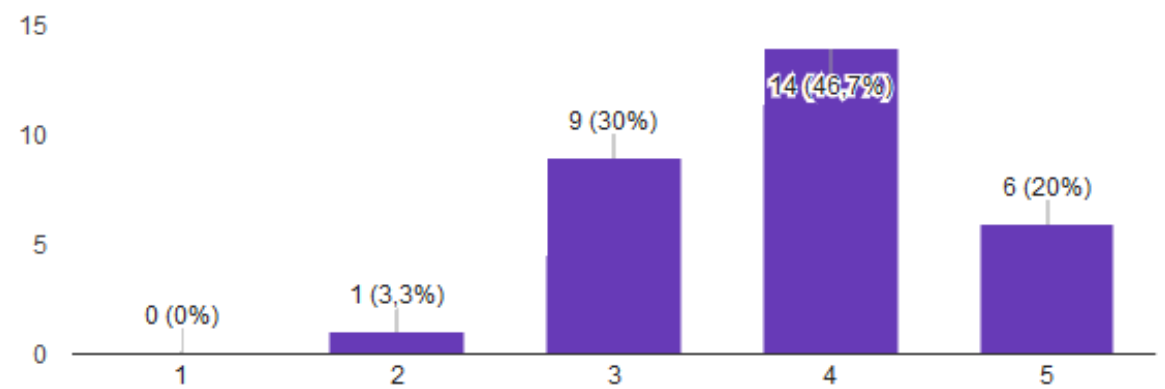

Bars chart 2.E-MAIL

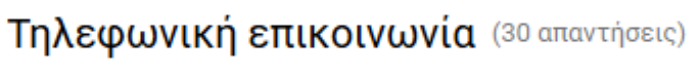

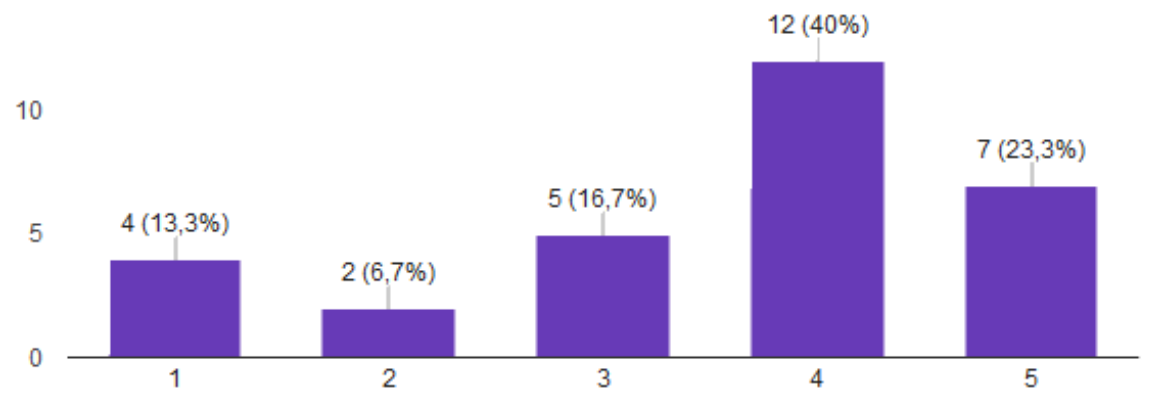


Bars chart 3. TELEPHONE CALLS

Forum (30 aravtíøєเৎ)

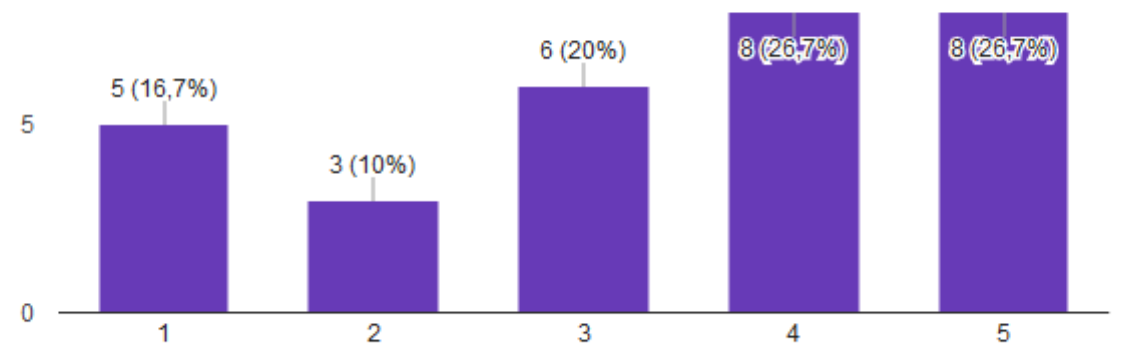

Bars chart 4.FORUM

Chat room (30 aravti்øeıc)

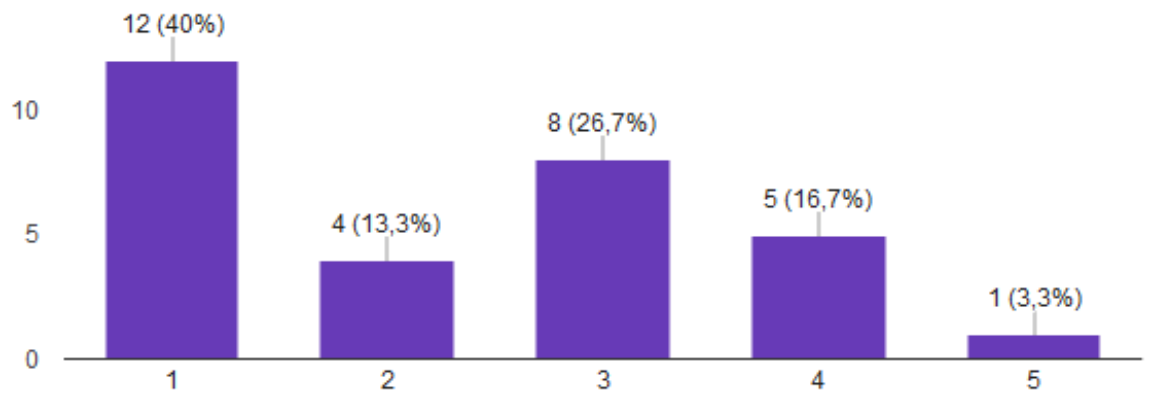

Bars 5.CHAT ROOM

Skype (30 aravti்бєıс)

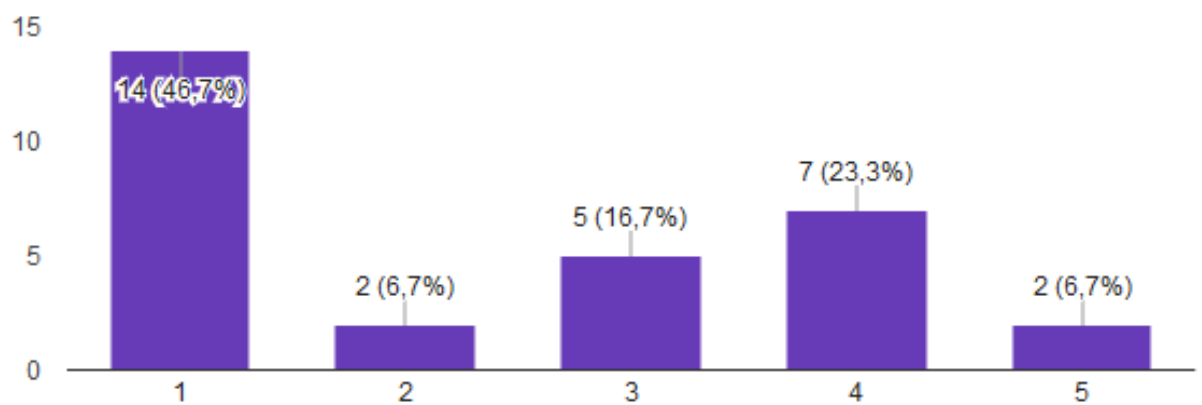

Bars 6.SKYPE 


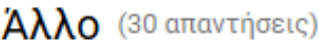

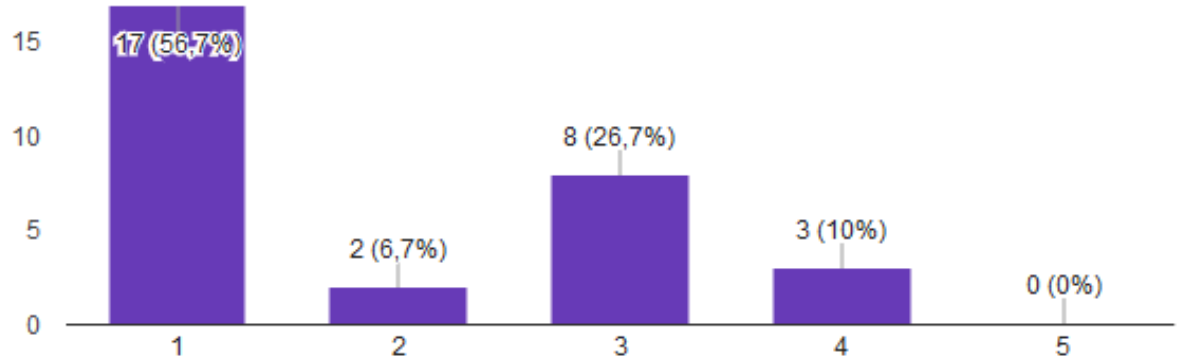

Bars 7.OTHER

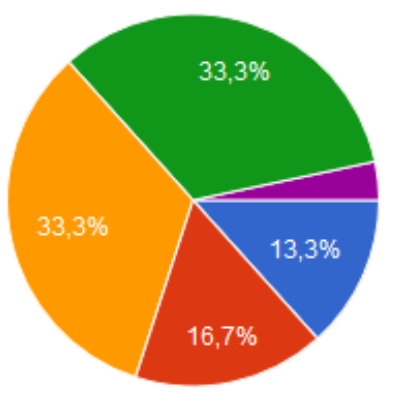

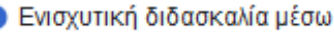

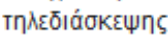

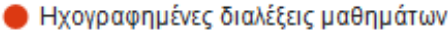

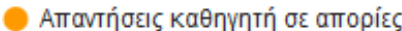

$\mu \varepsilon \dot{\sigma} \omega$ Tou forum

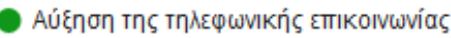

AMo

Circular Diagram 4. PERCENTAGE OF WAYS TO IMPROVE COMMUNICATION WITH THE LECTURER 